\title{
PHYSICAL MODELING OF HOT PLASTIC DEFORMATION PROCESS OF POWDER HIGH- SPEED STEEL ON THE GLEEBLE 3800 COMPLEX
}

\author{
Maxim ZAMOZDRA, Sergey GANIN, Valery TSEMENKO \\ ${ }^{1}$ Peter the Great St.Petersburg Polytechnic University, Department "Technology and materials research", \\ St.Petersburg, Russia, EU, zamozdra.m@gamil.com, s.v.ganin@gmail.com, tsemenko tim@mail.ru
}

https://doi.org/10.37904/metal.2020.3504

\begin{abstract}
In the present work, obtained billets from powder high-speed steel by the HIP method. Samples were tested at various speeds and degrees of hot plastic deformation, which are modeled on the Gleeble- 3800 complex. The total number of samples is 8 . The generalized experimental results cover almost the entire range of highspeed deformation modes of hot rolling mills and can be used to develop technological processes for metal forming when producing blanks for cutting tools in a wide size range.
\end{abstract}

Keywords: Physical modeling, powder metallurgy, plastic deformation, high-speed steel, extrusion

\section{INTRODUCTION}

Improving the quality of tools made of high-speed steels is currently being successfully solved by the methods of powder technology, the basis of which is compaction of atomized powders into practically non-porous preforms [1].

The manufacture of non-porous semi-finished products from atomized powders of high-speed steels is usually carried out by hot isostatic pressing (HIP) [2,3]. During the HIP process, the powders are pressed in special capsules (containers), which are thin-walled shells that are close in shape to the pressed products. Such products can have both simple shapes of cylindrical or flat blank and complex shapes of shaped parts. Typically, capsules are made from well-weldable low-carbon steel. After loading the powder into the capsule, it is hermetically sealed and evacuated.

High comprehensively uniform pressure in the gas chamber is created by the compressor. The calculated values of temperature and pressure are maintained at a constant level throughout the entire exposure time. After exposure, the product cools with a decrease in pressure.

High comprehensively uniform pressure in the gas chamber is created by the compressor. The calculated values of temperature and pressure are maintained at a constant level throughout the entire exposure time. After exposure, the product cools with a decrease in pressure.

The mechanical properties of powder high-speed steel billets after HIP are not high enough. So, for example, the flexural strength of specimens from R6M5 powder high-speed steels obtained by HIP after quenching and tempering is $2635 \mathrm{MPa}$, while the same steel produced by hot extrusion has a tensile strength of more than $4000 \mathrm{MPa}[4,5]$. This difference is due, first of all, to the fact that during HIP, the powder particles practically do not deform and the remnants of the oxide film on the surface of the particles reduce the surface of the clean contact between the particles. During extrusion, there is a significant deformation of the powder particles with rupture and dispersion of oxide films, which increases the surface of the pure interparticle contact. The consequence of this is to increase the strength and viscosity of the deformed metal. Therefore, the subsequent hot plastic deformation (forging or rolling) is necessary both for obtaining the required dimensions of the workpieces after the HIP, and for the formation of high physical and mechanical properties of the workpieces and, as a result, of the tool, especially the small-blade ones (drills, taps, mills). 
The aim of this work was the physical modeling of hot plastic deformation process of workpieces from powder R6M5 high-speed steel obtained by the HIP method in a steel shell; dependence assessment of the technological plasticity of the material in the studied temperature range $\left(900-1100{ }^{\circ} \mathrm{C}\right)$ on the speed and degree of deformation for the development of subsequent technologies for the hot plastic deformation of workpieces after HIP.

\section{EXPERIMENTAL}

\subsection{Materials and equipment}

To obtain the billet, high-speed steel powder R6M5 (Table 1) made by "Heganes - Eastern Europe" was used. The average particle size of the powder is 70 microns. The capsule was made of a seamless hot-deformed pipe with a diameter of $150 \mathrm{~mm}$ and a wall thickness of $5 \mathrm{~mm}$. The material of the capsule was low-carbon steel 20 (Table 2). The temperature of isothermal holding during the HIP $1150^{\circ} \mathrm{C}$, pressure $100 \mathrm{MPa}$.

Table 1 Chemical composition of high-speed steel powder R6M5

\begin{tabular}{|c|c|c|c|c|c|c|c|c|c|c|c|}
\hline $\mathbf{C}$ & $\mathbf{S i}$ & $\mathbf{M n}$ & $\mathbf{N i}$ & $\mathbf{S}$ & $\mathbf{P}$ & $\mathbf{C r}$ & Mo & W & V & Co & Fe \\
\hline $0.82-0.9$ & $\leq 0.5$ & $\leq 0.5$ & $\leq 0.4$ & $\leq 0.025$ & $\leq 0.03$ & $3.8-4.4$ & $4.8-5.3$ & $5.5-6.5$ & $1.7-2.1$ & $\leq 0.5$ & $\sim 80$ \\
\hline
\end{tabular}

Table 2 Chemical composition of low-carbon steel 20

\begin{tabular}{|c|c|c|c|c|c|c|c|c|c|c|c|}
\hline $\mathbf{C}$ & $\mathbf{S i}$ & $\mathbf{M n}$ & $\mathbf{N i}$ & $\mathbf{S}$ & $\mathbf{P}$ & $\mathbf{C r}$ & $\mathbf{C u}$ & As & $\mathbf{V}$ & Co & $\mathbf{F e}$ \\
\hline $0.17-0.24$ & $0.17-0.37$ & $0.35-0.65$ & $\leq 0.25$ & $\leq 0.04$ & $\leq 0.04$ & $\leq 0.25$ & $\leq 0.25$ & $\leq 0.08$ & - & - & $\sim 98$ \\
\hline
\end{tabular}
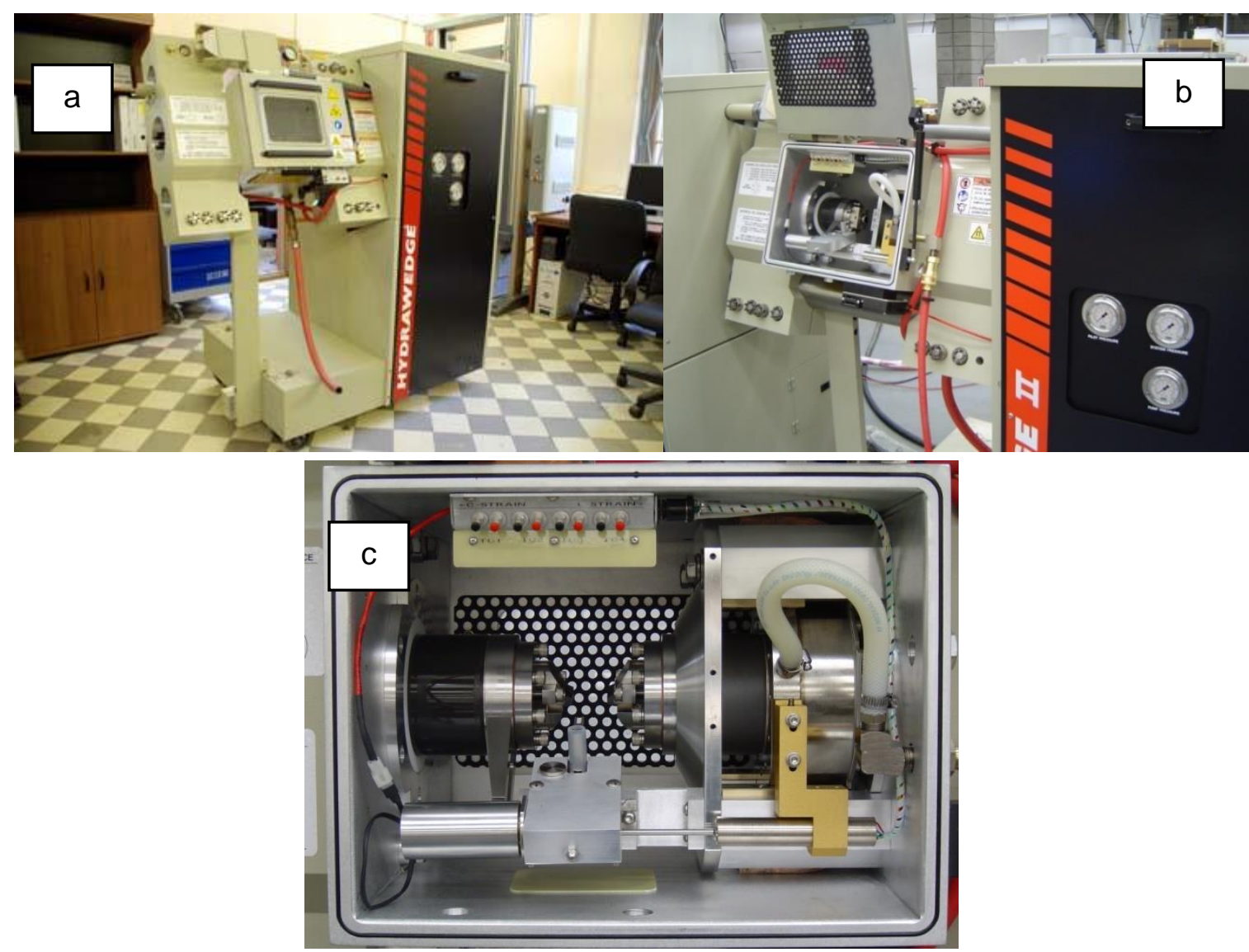

Figure 1 Hydrawedge module for performing impact tests $(a, b)$ and the view of his working chamber (c) 
After HIP, the capsule shell was removed by mechanical treatment. For research, cylindrical specimens with diameter $10 \mathrm{~mm}$ and length $15 \mathrm{~mm}$ were cut from high-speed powder steel.

Physical modeling was carried out on the test complex Gleeble-3800, which is able to carry out physical modeling of most processes of materials thermomechanical processing. In the present work, the Hydrawedge module was used for experiments (Figure 1).

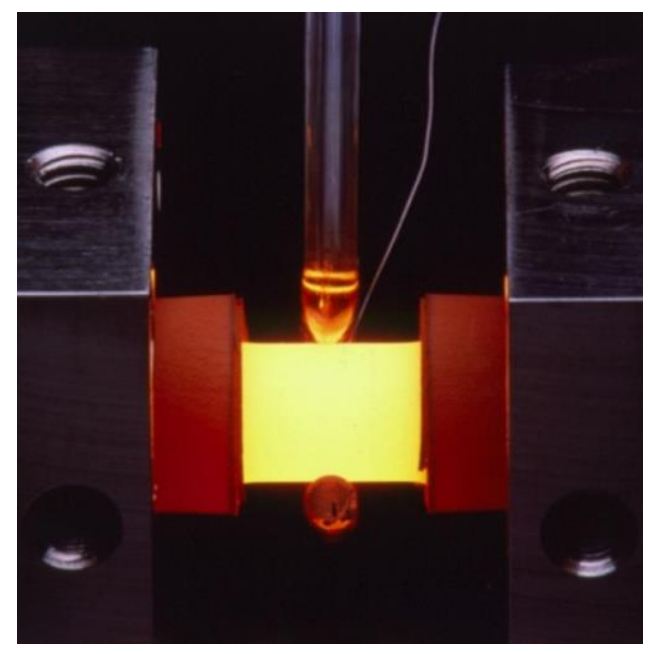

Figure 2 Image of the sample in the working chamber during testing

This module can be used for physical modeling of metal forming processes. It allows with high accuracy in the degree and speed of deformation to realize high-speed repeated deformation of the material at a given temperature mode, reproducing the temperature-deformation mode, in particular, multi-pass rolling, implemented on modern industrial multi-stand mills. The speed of the working beam can reach $2.5 \mathrm{~m} / \mathrm{s}$, which allows the deformation of the samples at speeds up to $200 \mathrm{~s}^{-1}$.

a)

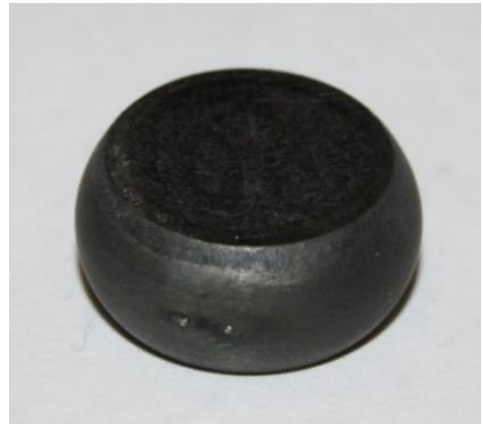

c)

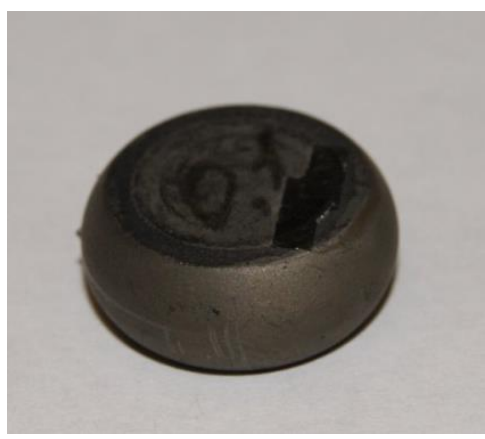

b)

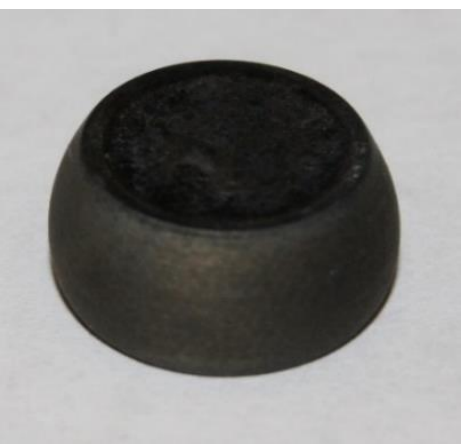

d)

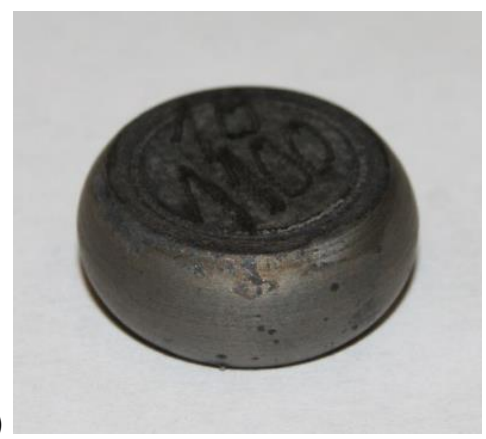

Figure 3 Appearance of tested samples: a - temperature $900^{\circ} \mathrm{C}$, strain rate $0.1 \mathrm{~s}^{-1} ; \mathrm{b}$ - temperature $900{ }^{\circ} \mathrm{C}$, strain rate $10 \mathrm{~s}^{-1} ; \mathrm{C}$ - temperature $1100^{\circ} \mathrm{C}$, strain rate $0.1 \mathrm{~s}^{-1} ; \mathrm{d}$ - temperature $1100{ }^{\circ} \mathrm{C}$, strain rate $10 \mathrm{~s}^{-1}$ 
In the present study, the simulation of hot plastic deformation was carried out on cylindrical samples of diameter $10 \mathrm{~mm}$ and $15 \mathrm{~mm}$ length by uniaxial compression between two flat strikers (Figure 2).

To protect the samples heated to high temperatures from surface oxidation, the tests were carried out in vacuum, and molybdenum foils were used to eliminate the welding of the samples to the strikers during deformation. Figure 3 shows the appearance of the samples after testing.

\section{RESULTS AND DISCUSSIONS}

In the Figure 4 shows the results of an experimental study of the plastic flow of powder high-speed steel R6M5 in the temperature range of hot plastic deformation at various rates and degrees of deformation, combined as a summary diagram of loading samples.

Analysis and generalization of the presented simulation results allows us to assume that the level of technological plasticity in the studied temperature range $\left(900-1100{ }^{\circ} \mathrm{C}\right)$ is high enough to produce true deformation to the degree of 0.8 (compression from 15 to $6.5 \mathrm{~mm}$ on the samples studied) without formation of defects in the form of cracks in the entire range of strain rates used on modern forging and rolling equipment.

\section{CONCLUSION}

Thus, in this work, we obtained a billet of powder high-speed steel by the HIP method, tested the samples at various rates and degrees of hot plastic deformation, which were modeled on the Gleeble-3800 complex. The generalized experimental results cover almost the entire range of high-speed modes of deformation of hot rolling mills and can be used to develop technological processes for metal forming when producing blanks for cutting tools in a wide size range.

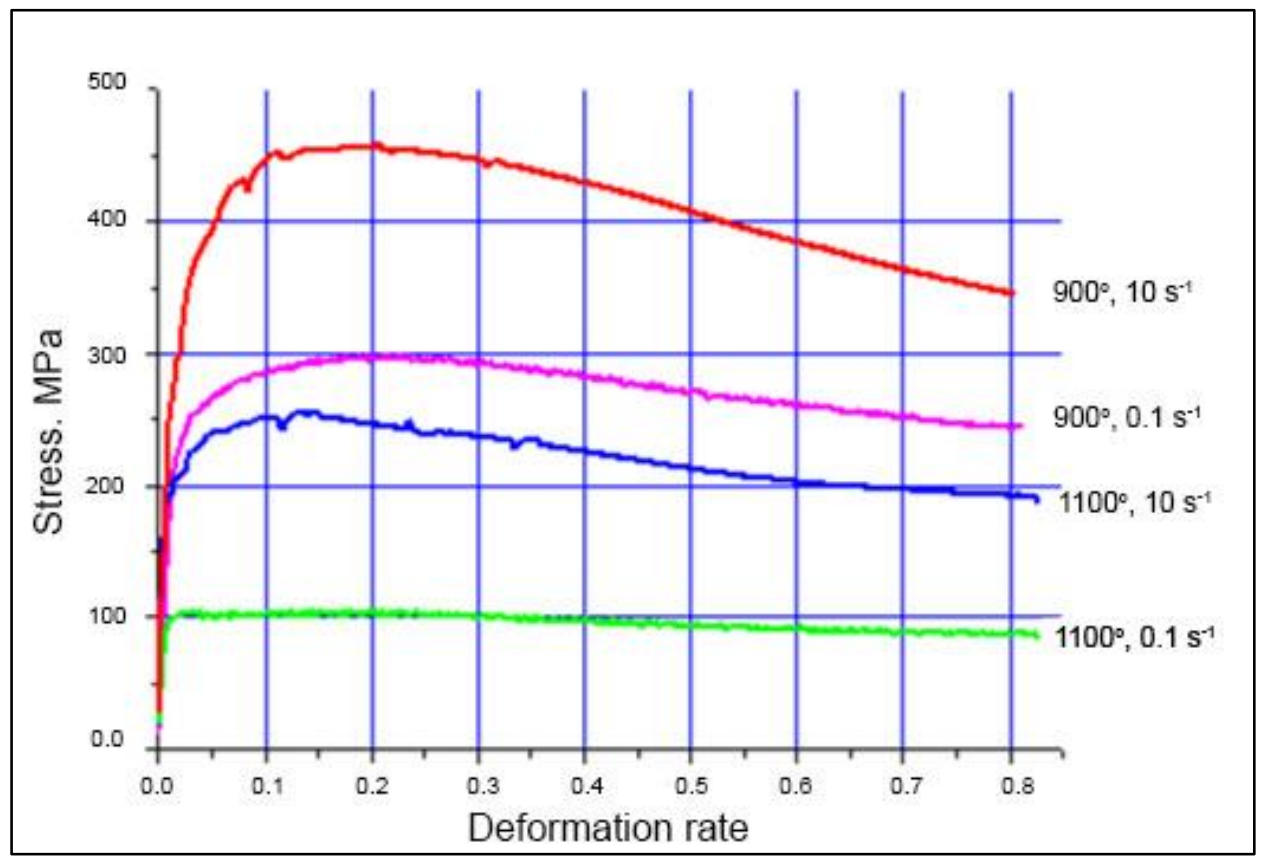

Figure $4 \mathrm{~A}$ summary diagrams of stresses on the deformation degrees which show the results of an experimental study of powder high-speed steel R6M5 plastic flow

\section{ACKNOWLEDGEMENTS}

The reported study was funded by RFBR, project number 19-33-90241. 


\section{REFERENCES}

[1] NAUMOV, A.A., BEZOBRAZOV, Y.A., CHERNIKOV, E.V. Development of Hot Rolling Schedules for Lean Alloyed Pipeline Steel X80 Produced on Continuous Mill 2000. Materials Science Forum. 2014, vol. 783, pp. 938943.

[2] AGEEV S.V., GIRSHOV V.L. Hot isostatic pressing in powder metallurgy. Metalworking. 2015, vol. 4 (88), pp. 5660.

[3] MIRONENKO, V.N., VASENEV, V.V., PETROVICH, S.Y., MYSHLYAEV, I.V. Structure and properties of compact workpieces and bars made of sintered aluminium alloy CAC-1. Tsvetnye Metally. 2018, vol. 4, pp. 86-91.

[4] BEHRENS, B.A., BOUGUECHA, A., VUCETIC, M., PESHEKHODOV, I., KAZHAI, M., GANIN, S., MATVEEV, M. Physical simulation of precipitation hardened ferrite-pearlite steels during hot deformation processing. Materials Physics and Mechanics. 2016, vol. 25, no. 1, pp. 9-15.

[5] TSEMENKO, V.N., GANIN, S.V., PHUC, D.V. Research and simulation of the deformation process of dispersion hardened powder in a capsule. Materials Physics and Mechanics. 2016, vol. 25, no. 1, pp. 68-75. 